\title{
Studi Perbandingan Return Saham Perusahaan Perbankan dan Perusahaan Pertambangan di Bursa Efek Indonesia
}

\author{
Endah Tri Wahyuningtyas \& Mardiyah Anugraini \\ endahtri@unusa.ac.id\&mardiyah@unusa.ac.id
}

\begin{abstract}
This research was conducted to answer investors' doubts in investing their capital in the stock market, the large number of stock sectors offered in the stock market made investors have to analyze properly before deciding which sector of the stock promises the greatest profit and has the best growth. In this study the author tries to compare between the stock returns of the banking and financial sector in Indonesia securities. And the results of the research can be concluded that the stock returns of banking companies are based on capital gains higher than mining companies.
\end{abstract}

Keywords: stock returns, finance, mining

\section{PENDAHULUAN}

Semua investor selalu menginginkan agar investasi yang ditanamkan mendapatkan tingkat pengembalian yang optimal atas investasi yang ditanamkan. Di Indonesia instrumen investasi sangat bervariasi yang dikeluarkan perusahaan baik itu berbentuk saham maupun obligasi serta instrumen yang lainnya seperti halnya Surat Utang Negara atau SUN. Pada tahun 2017 pertumbuhan pasar modal Indonesia sangat pesat terutama di sektor pertambangan dan perbankan seiring dengan kebijakan pemerintah yang melakukan program tax amnesti akhir tahun 2017 membawa dampak besar terhadap capital inflow yang mendorong naiknya permintaan saham sektor keuangan maupun perbankan.

Investor selalu melakukan perbandingan saham apa saja yang memberikan return terbaik serta memiliki pertumbuhan yang cepat, baik itu sektor keuangan, pertambangan, maupun sektor properti. Pemilihan atas investasi tersebut membutuhkan pertimbangan yang matang, mengingat kesalahan dalam pemilihan instrumen saham dapat berdampak pada tingkat pendapatan yang didapatkan. Pada tahun 2016 kinerja saham sektor konsumen tercatat memiliki kinerja paling baik yaitu tumbuh sebesar $81 \%$ disusul saham sektor keuangan tumbuh sebesar 73\%, selanjutnya saham sektor perdagangan dan jasa investasi tumbuh 72\%. Sedangkan sektor industri dasar dan kimia tercatat tumbuh sebesar 71\% disusul sektor aneka industri sebesar $67 \%$ dan sektor properti dan konstruksi tumbuh 64\%. Sebaliknya, ada beberapa sektor tercatat mengalami penurunan yaitu agrikultur turun sebesar $67 \%$, disusul infrastruktur atau transportasi sebesar 64\%, selanjutnya pertambangan mengalami penurunan sebesar 54\% (idx.co.id).

Dilansir dari kontan.co.id memberitakan bahwa salah satu sektor terkuat sepanjang tahun 2018 adalah sektor pertambangan dan sektor keuangan di mana indeks harga saham gabungan (IHSG) keduanya masih aktif bergejolak, terkoreksi pasar keuangan hingga 4,5\% sejak awal tahun 2019. Penelitian Ulupui (2017) menyatakan bahwa rasio keuangan memiliki pengaruh terhadap return saham, selanjutnya Suharli (2005) menemukan bahwa rasio utang serta tingkat risiko berdampak terhadap return saham.

Investor dalam memilih dan menganalisis saham sektor mana yang akan dipilih, biasanya 
menggunakan dua pendekatan analisis yaitu pendekatan teknikal dan fundamental. Pendekatan teknikal menggunakan analisis pergerakan harga saham yang didasarkan pada indikator tertentu (Prasetya Yusi, 2018) dan pendekatan fundamental lebih mengarah pada hal yang berkaitan dengan kondisi perusahaan yaitu bisa melalui laporan keuangan dan kinerja sahamnya. Kinerja saham bisa diukur melalui peningkatan return saham. Penelitian Prasetya Yusi (2018) menemukan bahwa tidak semua perusahaan di Jakarta Islamic Index mempunyai return yang positif. Perusahaan yang layak dijadikan pilihan berinvestasi adalah perusahaan yang memiliki return investasi di atas nilai investasi dan di atas bunga deposito.

Oleh karena itu, paper ini menekankan pada analisis distribusi pergerakan return saham perusahaan perbankan dan pertambangan yang terdaftar di LQ45 selama periode 2014-2017 sebagai acuan fundamental sebelum memilih berinvestasi. Menghitung return saham yang akan diperoleh investor melalui capital gain. Lalu besarnya return saham dianalisis melalui pergerakan harga saham. Harapannya berdasarkan analisis return saham dan harga saham ini dapat ditentukan kriteria perusahaan mana yang layak menjadi tempat investasi bagi investor.

\section{Kajian Teoretis}

Return saham merupakan tolok ukur investor untuk menanamkan investasi mereka karena return saham dapat diartikan sebagai reward atas keberanian investor yang menanggung risiko atas investasinya. Ada dua reward yang akan diperoleh oleh seorang pemilik dana (Fadlillah Muhammad, 2006).

a. Dividen diartikan sebagai suatu pembagian keuntungan yang diberikan kepada stakeholder. Jumlah dividen yang diberikan ke pemilik dana akan dipengaruhi oleh besaran kepemilikan saham investor.

b. Capital gain diperoleh dari selisih antara harga beli dan harga jual. Terbentuk dari aktivitas perdagangan saham.

Return yang sudah terjadi di masa lalu dan dihitung berdasarkan data historis merupakan pengembalian secara keseluruhan dari jumlah investasi kita dalam suatu periode tertentu. Capital gain dapat menunjukkan apresiasi pasar pada kinerja perusahaan. Oleh karena itu, penelitian ini menggunakan capital gain sebagai alat ukur return saham.

Prasetia Yusi (2018) meneliti saham perusahaan sebagai acuan untuk berinvestasi berdasarkan return saham dan laporan keuangan. Hasilnya bahwa tidak semua perusahaan menghasilkan return positif, ada beberapa perusahaan yang memberikan return negative. Penelitian ini menggunakan pendekatan kualitatif deskriptif. Sedangkan penelitian yang dilakukan oleh Rahma, A.A., Elfiswandi, E., \& Putri, I.P. (2017) menggunakan uji paired sample T-Test menghasilkan bahwa pada perusahaan perbankan tidak terdapat perbedaan saham sebelum dan sesudah right issue.

Barberis, N., Mukherjee, A., \& Wang, B. (2016) menelaah 46 perusahaan di bursa saham US dan menemukan bahwa apabila pergerakan return saham di masa lalu itu diprediksi bernilai tinggi (rendah) maka kedepannya menghasilkan return saham yang rendah (tinggi) dan rata-rata. Hal ini didukung oleh teori prospek.

\section{Teori Prospek (Prospect Theory)}

Brown et al. (2002) menyatakan bahwa teori prospek dalam istilah akuntansi ditemukan oleh Kahneman dan Tversky (1979). Teori prospek merupakan teori yang menjelaskan bahwa bagaimana calon investor membuat keputusan 
dalam berinvestasi jika berada dalam kondisi ketidakpastian (uncertainty) pada risiko yang akan terjadi atas pilihan yang diambil (Chiu dan Wu, 2011). Astika, I.B.P. (2017) memberikan gambaran bahwa teori prospek fokus pada pentingnya suatu acuan atau pedoman untuk menentukan pilihan dari berbagai pilihan yang ada beserta dengan segala risiko dan prospek ke depannya.

\section{METODE PENELITIAN}

\section{Jenis Penelitian}

Dalam penelitian ini penulis menggunakan penelitian kualitatif deskriptif yaitu menganalisis tentang suatu keadaan atau peristiwa keuangan perusahaan perbankan dan pertambangan di Bursa Efek Indonesia sehingga dapat dijadikan acuan dalam mengambil keputusan berinvestasi.

\section{Populasi dan Sampel}

Penelitian ini dilakukan pada perusahaan tambang dan perbankan yang terdaftar di BEI yang masuk dalam kategori LQ45 atau 45 saham teraktif di BEI, dengan catatan tidak pernah melakukan stock split pada periode tersebut sehingga dapat dilakukan analisis secara akurat.

\section{Metode Analisis Data}

Untuk menganalisis dan membuktikan tingkat return antara perusahaan tambang dan perusahaan perbankan di Bursa Efek Indonesia maka penelitian ini dilakukan analisis trend dengan menggunakan data harga saham tahun 2013 sampai tahun 2017. Return rata-rata (average return) dihitung dengan menggunakan rumus:

$$
\mathrm{AR}=\left(\mathrm{R}_{1}+\mathrm{R}_{2}+\ldots+\mathrm{R}_{\mathrm{n}}\right) / \mathrm{n}
$$

Keterangan:

$\mathrm{AR}=$ Average return

$\mathrm{R}_{1}=$ Return periode ke-1

$\mathrm{R}_{2}=$ Return periode ke-2

$\mathrm{R}_{\mathrm{n}}=$ Return periode ke- $\mathrm{n}$

$\mathrm{n}=$ Total jumlah periode

\section{HASIL PENELITIAN DAN PEMBAHASAN}

Penelitian ini mencoba melakukan kajian tentang return saham secara riil yang diterima oleh investor, return saham dilihat berdasarkan keuntungan berdasarkan capital gain atau selisih antara harga jual dibandingkan dengan harga beli yang dilakukan oleh investor. Penelitian ini berfokus pada saham LQ45 atau 45 saham teraktif yang ada di bursa efek Indonesia diambil berdasarkan laporan kinerja emiten yang dipublikasikan di idx.

Dari pengumpulan data saham LQ45, diambil perusahaan pertambangan dan perbankan dari tahun 2014 sampai dengan tahun 2017 dengan kriteria kurun tahun tersebut tidak melakukan stock split sehingga didapatkan hasil penelitian yang akurat. Setelah dikelompokkan berdasarkan jenisnya saham LQ45 yang bisa dilakukan pengukuran return saham secara riil adalah sebagai berikut.

Tabel 1 Data Saham Data Perusahaan Tambang dan Perbankan

\begin{tabular}{|c|c|c|}
\hline No. & $\begin{array}{c}\text { SAHAM } \\
\text { PERBANKKAN }\end{array}$ & SAHAM PERTAMBANGAN \\
\hline 1 & BBCA & ADRO \\
\hline 2 & BBNI & ITMG \\
\hline 3 & BBTN & ANTM \\
\hline 4 & BJBR & INDY \\
\hline
\end{tabular}

Sumber: idx diolah

Dari tabel tersebut dapat penulis sajikan data harga saham tahunan perusahaan pertambangan dan perbankan yang masuk kategori tersebut adalah sebagai berikut. 
Tabel 2

Data Saham Perbankan

\begin{tabular}{|l|r|r|r|r|}
\hline & \multicolumn{1}{|c|}{2014} & \multicolumn{1}{c|}{2015} & \multicolumn{1}{c|}{2016} & \multicolumn{1}{c|}{2017} \\
\hline BBCA & 13.125 & 13.200 & 15.500 & 21.900 \\
\hline BBNI & 6.100 & 4.990 & 5.525 & 9.900 \\
\hline BBTN & 1.025 & 1.295 & 1.740 & 3.570 \\
\hline BJBR & 730 & 755 & 3.390 & 2.400 \\
\hline
\end{tabular}

Sumber: idx diolah

Harga saham bank BCA pada tahun 2014 tercatat 13.125 mengalami penurunan pada tahun 2015 sebesar 13.200. Selanjutnya, saham Bank BCA pada tahun 2016 tercatat naik sebesar 1.550 berlanjut sampai tahun 2017 saham bank BCA naik sebesar 21.900 di akhir tahun 2017. Artinya bahwa jika investor memilih saham BBCA maka investor mengalami keuntungan yang besar. Selanjutnya, saham Bank BNI tahun 2014 tercatat sebesar 6.100 turun tajam di tahun 2015 saham Bank BNI dijual pada kisaran 4.990 per lembar, untuk tahun 2016 saham Bank BNI mengalami sedikit kenaikan sebesar 5.525 dan di tahun 2017 naik sangat tajam yaitu 9.900. Saham BTN tahun 2014 tercatat 1.025 naik 1.295 di tahun 2015 selanjutnya harga saham Bank BTN terus naik menjadi 1.740 pada tahun 2016 berlanjut 2017 mencapai 3.570. Bank BJBR atau lebih dikenal dengan Bank Jabar Banten tahun 2014 harga saham BJBR tercatat 730 dan di tahun 2015 harga saham BJBR sebesar 755, tahun 2016 melejit menjadi 3.390 namun di tahun 2017 saham BJBR turun menjadi 2.400 , ini artinya investor mengalami kerugian saat berinvestasi di BJBR. Untuk lebih jelasnya pergerakan saham perbankan dapat dilihat pada Gambar 1.

Selanjutnya data harga saham pertambangan yang masuk ke dalam LQ45 pergerakan sahamnya dapat dilihat pada Tabel 3.

Perusahaan tambang ADRO tahun 2014 mempunyai harga saham 1.040 turun drastis di tahun 2015 sebesar 515 kemudian saham Adaro naik tajam di tahun 2016 sebesar 16.875 dan tahun 2017 saham Adaro kembali naik tajam sebesar 1.860. Harga saham ITMG tahun 2014 sebesar 15.375 turun drastis di tahun 2015 menjadi 5.725 dan tahun 2015 saham ITMG menguat

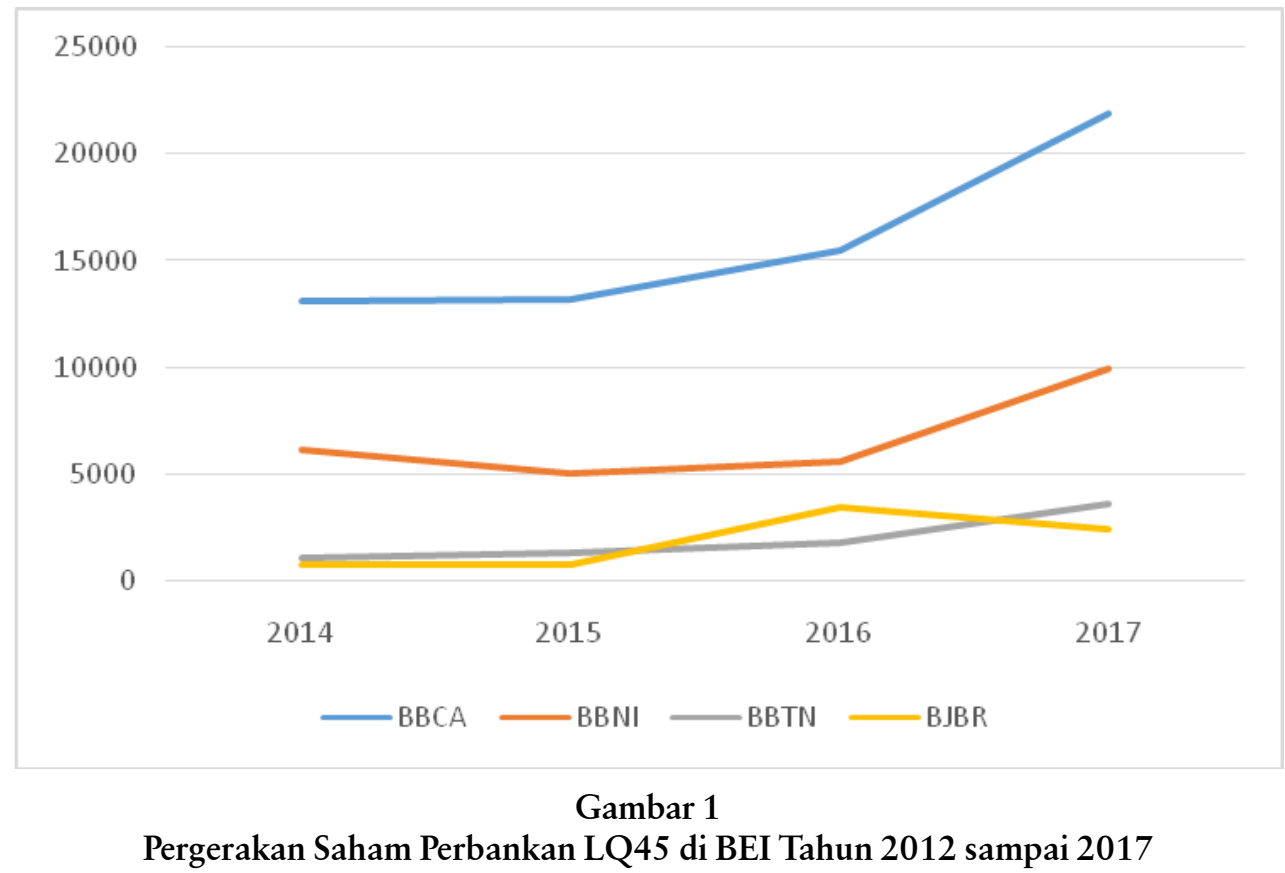


Tabel 3

Data Saham Tambang

\begin{tabular}{|l|r|r|r|r|}
\hline & \multicolumn{1}{|c|}{2014} & \multicolumn{1}{c|}{2015} & \multicolumn{1}{c|}{2016} & \multicolumn{1}{c|}{2017} \\
\hline ADRO & 1.040 & 515 & 1.695 & 1.860 \\
\hline ITMG & 15.375 & 5.725 & 16.875 & 20.700 \\
\hline ANTM & 1.065 & 314 & 895 & 625 \\
\hline INDY & 510 & 110 & 705 & 3.060 \\
\hline
\end{tabular}

Sumber: idx diolah

sebesar 16.875 berlanjut tahun 2017 saham ITMG tercatat naik sebesar 20.700. Harga saham Antam atau ANTM sebesar 1.065 pada tahun 2014 turun drastis saham Antam menjadi 314 di tahun 2015. Selanjutnya, saham ANTM naik 895 tahun 2016 dan di tahun 2017 turun tipis sebesar 625. Sedangkan saham INDY tahun 2015 sebesar 510 turun drastis menjadi 110 dan tahun 2016 saham INDY naik tajam di angka 705 lalu terus di tahun 2017 kembali mengalami naik tajam sebesar 3.060. Untuk melihat pergerakan harga saham perusahaan pertambangan dapat dilihat pada Gambar 2.
Gambar 2 menggambarkan pergerakan saham pertambangan kurun waktu 2014 sampai 2017. Untuk dapat dianalisis selanjutnya dilihat return saham dengan cara membandingkan harga saham tahun $t$ dengan tahun sebelumnya $t-1$ sehingga dapat dilihat capital gain yang diterima oleh investor. Return saham sektor pertambangan masih terlihat bergejolak karena memang disinyalir seputar harga komoditas barang. Apalagi Cina sebagai produsen batu bara terbesar yang menggunakan batu bara sebagai energi listrik di negaranya akan membuat kebijakan baru yaitu menurunkan pemakaian energi batu bara sebagai salah

Tabel 4

Data Return Saham Perbankan LQ45 di BEI Tahun 2012 sampai 2017

\begin{tabular}{|l|r|r|r|r|r|r|c|}
\hline & \multicolumn{1}{|c|}{$\mathbf{2 0 1 4}$} & \multicolumn{1}{c|}{$\mathbf{2 0 1 5}$} & \multicolumn{1}{|c|}{$\mathbf{2 0 1 6}$} & \multicolumn{1}{c|}{$\mathbf{2 0 1 7}$} & \multicolumn{1}{c|}{ R1 } & \multicolumn{1}{c|}{ R2 } & R3 \\
\hline BBCA & 13.125 & 13.200 & 15.500 & 21.900 & 75 & 2.300 & 6.400 \\
\hline BBNI & 6.100 & 4.990 & 5.525 & 9.900 & -1.110 & 535 & 4.375 \\
\hline BBTN & 1.025 & 1.295 & 1.740 & 3.570 & 270 & 445 & 1.830 \\
\hline BJBR & 730 & 755 & 3.390 & 2.400 & 25 & 2.635 & -990 \\
\hline
\end{tabular}

Sumber: idx diolah

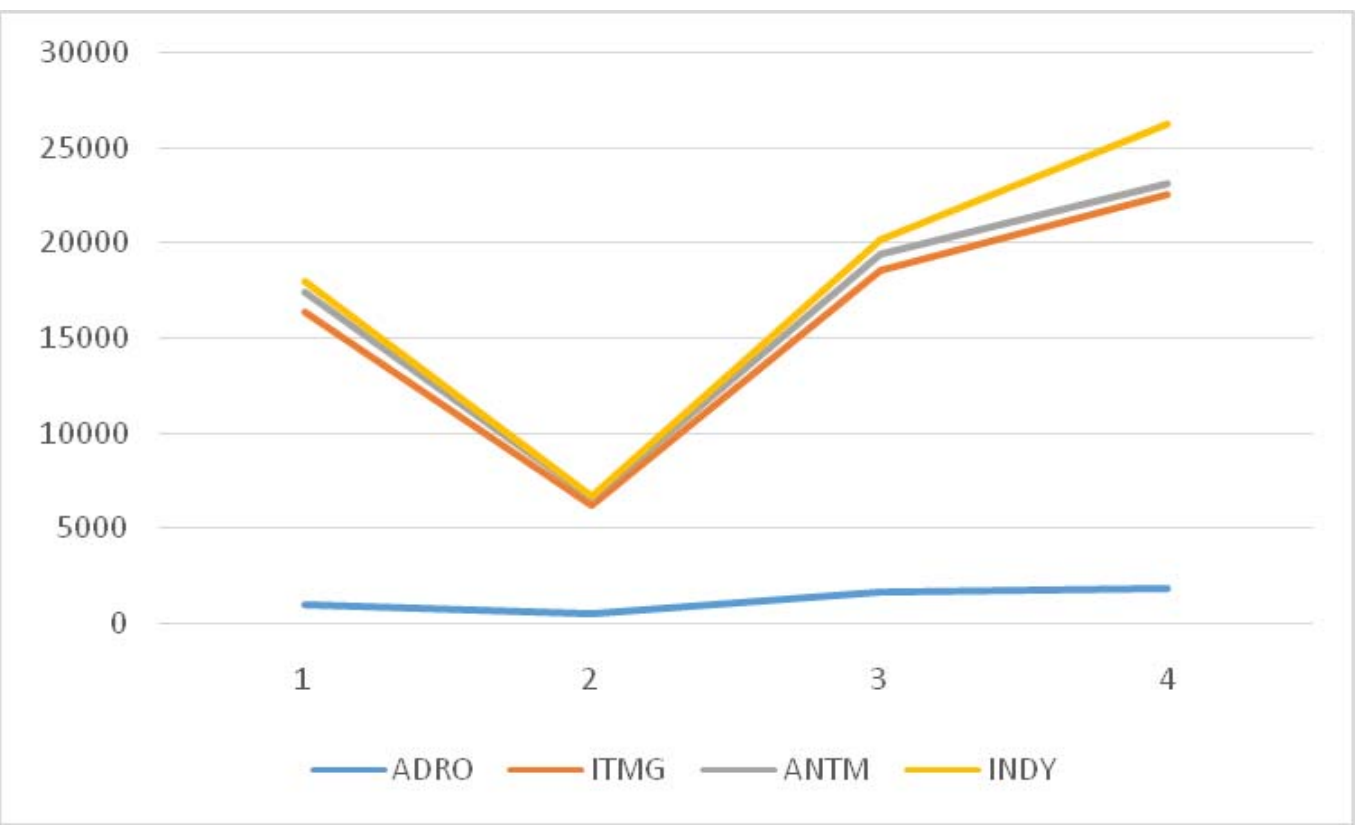

Gambar 2

Pergerakan Saham Tambang LQ45 di BEI Tahun 2012 sampai 2017 
satu upaya penekanan tingkat polusi di negara tersebut sehingga dengan kebijakan Cina tersebut berdampak pada return saham perusahaan pertambangan.

Untuk dapat mengetahui return saham yang diterima oleh investor dengan cara melakukan perbandingan harga saham setiap tahunnya. Dari data di atas dapat dilihat bahwa pada saham perbankan tahun 2015 capital gain yang paling tinggi adalah dari bank BBTN dengan nilai capital gain sebesar 270, sedangkan loss atau kerugian yang paling besar dialami oleh Bank BBNI sebesar -1110. Untuk tahun 2016 capital gain paling tinggi di perbankan adalah Bank BJBR dengan nilai keuntungan mencapai 2.635. Sedangkan capital gain paling rendah adalah bank BBTN sebesar 445 untuk tahun 2017 tingkat capital gain tertinggi yaitu bank BBCA dengan keuntungan sebesar 6.400 sedangkan kerugian terbesar dialami bank BJBR yaitu sebesar -990 .

Tabel 5

Data Return Saham Perusahaan Tambang LQ45 di BEI Tahun 2012 sampai 2017

\begin{tabular}{|l|r|r|r|r|r|r|c|}
\hline & $\mathbf{2 0 1 4}$ & $\mathbf{2 0 1 5}$ & \multicolumn{1}{c|}{$\mathbf{2 0 1 6}$} & \multicolumn{1}{c|}{$\mathbf{2 0 1 7}$} & \multicolumn{1}{c|}{ R1 } & \multicolumn{1}{c|}{ R2 } & R3 \\
\hline ADRO & 1.040 & 515 & 1.695 & 1.860 & -525 & 1.180 & 165 \\
\hline ITMG & 15.375 & 5.725 & 16.875 & 20.700 & -9.650 & 11.150 & 3.825 \\
\hline ANTM & 1.065 & 314 & 895 & 625 & -751 & 581 & -270 \\
\hline INDY & 510 & 110 & 705 & 3.060 & -400 & 595 & 2.355 \\
\hline
\end{tabular}

Sumber: idx diolah

Untuk saham pertambangan capital gain tahun 2015 semua perusahaan pertambangan mengalami capital loss atau kerugian, sedangkan tingkat kerugian yang paling besar adalah saham ITMG rugi sebesar 9.650. Tahun 2016 semua perusahaan pertambangan mencatatkan capital gain dan ITMG membukukan keuntungan yang paling tinggi yaitu 11.150, untuk tahun 2017 tingkat capital gain yang paling tinggi adalah ITMG sedangkan yang mengalami kerugian adalah ANTM dengan capital loss sebesar -270. Ini menandakan investor saat menanamkan investasi di ANTM mengalami kerugian karena tingkat return menurun drastis bahkan minus.

Untuk mengukur tingkat return saham investasi saham selama lima tahun yaitu dengan cara menghitung harga saham tahun kelima dikurangi dengan harga pembelian pada tahun pertama sehingga dapat diketahui capital gain yang diterima oleh investor, berikut ini tabel tingkat return saham perbankan selama lima tahun.

Tabel 6

Data perhitungan Return Saham Perbankkan LQ45 di BEI Tahun 2012 Sampai 2017

\begin{tabular}{|l|r|r|r|r|r|r|}
\hline & 2014 & \multicolumn{1}{|c|}{2015} & 2016 & \multicolumn{1}{c|}{2017} & R-total & $\%$ \\
\hline BBCA & 13.125 & 13.200 & 15.500 & 21.900 & 8.775 & 66,85 \\
\hline BBNI & 6.100 & 4.990 & 5.525 & 9.900 & 3.800 & 62,29 \\
\hline BBTN & 1.025 & 1.295 & 1.740 & 3.570 & 2.545 & 248,29 \\
\hline BJBR & 730 & 755 & 3.390 & 2.400 & 1.670 & 228,76 \\
\hline \multicolumn{10}{c}{ Total } & $606,21 \%$ \\
\end{tabular}

Dari Tabel 6 return yang diperoleh investor bank BBCA selama lima tahun mendapatkan keuntungan sebesar 8775 ribu rupiah per lembar atau 66,85\%. Untuk bank BBNI total return yang didapatkan sebesar 3800 atau 62,29\% sedangkan return Bank BTN mendapatkan keuntungan sebesar 2545 atau 248,29\% dan Bank BJBR mencatatkan return sebesar 1670 atau $228,76 \%$. Dari hasil tersebut return saham investasi selama lima tahun pendapatan capital gain yang terbesar diduduki oleh bank BBTN dengan mencatat keuntungan sebesar $248 \%$ dalam lima tahun.

Untuk perhitungan return saham pertambangan selama lima tahun penulis sajikan sebagai berikut. 
Tabel 7

Data perhitungan Return Saham Pertambangan LQ45 di BEI Tahun 2012 Sampai 2017

\begin{tabular}{|l|r|r|r|r|r|r|}
\hline & $\mathbf{2 0 1 4}$ & $\mathbf{2 0 1 5}$ & $\mathbf{2 0 1 6}$ & $\mathbf{2 0 1 7}$ & R-total & \multicolumn{1}{c|}{$\%$} \\
\hline ADRO & 1040 & 515 & 1695 & 1860 & 820 & 78,84 \\
\hline ITMG & 15375 & 5725 & 16875 & 20700 & 5325 & 34,63 \\
\hline ANTM & 1065 & 314 & 895 & 625 & -440 & $-41,31$ \\
\hline INDY & 510 & 110 & 705 & 3060 & 2550 & 500 \\
\hline
\end{tabular}

ADRO mempunyai capital gain selama lima tahun sebesar 820 atau meningkat $78,84 \%$, sedangkan ITMG mendapatkan total capital gain sebesar 5325 atau 34\% dari investasi yang ditanamkannya. Namun ANTM justru mengalami capital loss atau kerugian yang cukup besar yaitu -440 per lembar saham atau 41,31\% dari modal semula. Selanjutnya, INDY mendapatkan capital gain yang sangat besar yang menjadikan INDY memiliki keuntungan paling besar dibanding saham tambang yang lain yaitu sebesar 2550 atau 500\%. Ini sejalan dengan penelitian Prasetya Yusi (2018) bahwa tidak semua perusahaan yang listed di JII mempunyai return positif, ada beberapa dari mereka yang mengalami capital loss.

Untuk mengetahui tingkat return yang paling besar atau paling menguntungkan dari capital gain antara perusahaan pertambangan dan perusahaan pertambangan di BEI untuk periode tahun 2014 sampai dengan 2017 dilakukan perhitungan rata-rata persentase capital gain yang diterima selama lima tahun sebagaimana perhitungan di atas dapat dilihat bahwa rata-rata persentase saham perbankan tercatat sebesar $151,55 \%$ keuntungan yang didapat dari capital gain, sedangkan perusahaan tambang mendapatkan rata-rata persentase sebesar 143,04\% dalam lima tahun sehingga dapat disimpulkan bahwa perusahaan perbankan periode 2014 sampai 2017 memiliki rata-rata capital gain lebih tinggi bila dibandingkan dengan perusahaan pertambangan.
Berdasarkan hasil di atas maka sebagai seorang investor sebaiknya harus mengevaluasi strategi penanaman investasinya. Dia harus melihat data history return saham sebuah perusahaan sebelum mengambil keputusan. Tingkat return saham yang positif dan selalu meningkat dapat dijadikan tolak ukur bahwa perusahaan tersebut layak dijadikan tempat berinvestasi. Namun jika return sahamnya bergejolak maka teori prospek dapat dijadikan landasan. Barberis, N., Mukherjee, A., \& Wang, B. (2016) menyatakan bahwa beberapa pemilik modal berpikir bahwa sebuah saham yang data history return sahamnya memiliki nilai tinggi maka menghasilkan return saham ke depannya rendah, begitupun sebaliknya. Hal ini dijumpai pada sebagian besar perusahaan dari empat puluh enam pasar saham US.

\section{SIMPULAN DAN SARAN}

\section{Simpulan}

Dari pembahasan tersebut dapat disimpulkan sebagai berikut.

1. Perusahaan perbankan pada periode tahun 2014 sampai 2017 mencatatkan keuntungan dari capital gain sebesar 151,55\%. Dan yang menduduki peringkat pertama adalah bank BBTN dengan mencatatkan capital gain sebesar 248,29\%

2. Perusahaan pertambangan pada periode tahun 2014 sampai 2017 mampu memberikan tingkat return saham atau keuntungan dari capital gain dengan rata-rata sebesar 143,04\%, dengan menempatkan saham INDY dengan menghasilkan capital gain sebesar 500\% selama 5 tahun.

3. Dari hasil perhitungan dapat diketahui bahwa tingkat return saham atau capital gain ratarata perusahaan perbankan lebih baik dari rata-rata perusahaan pertambangan yaitu 
sebesar 151,55 sedangkan rata-rata capital gain perusahaan tambang sebesar 143,04.

\section{Saran}

Berdasarkan kesimpulan maka saran penulis adalah sebagai berikut.

1. Investor agar dapat melakukan keputusan investasi dengan melihat trend rata-rata return yang diperoleh dari setiap sektor saham sehingga terhindar dari kerugian.

2. Dengan melihat rata-rata keuntungan, investor dapat membuat portofolio sehingga dapat memperoleh keuntungan investasi.

3. Investor agar mencermati setiap pergerakan saham sehingga mendapatkan informasi saham yang menguntungkan atau tidak.

\section{DAFTAR RUJUKAN}

Aryaningsih, Y.Y., Fathoni, A., \& Harini, C. 2018. Pengaruh Return on Asset (ROA), Return On Equity (ROE) dan Earning per Share (EPS) Terhadap Return Saham pada Perusahaan Consumer Good (Food And Beverages) yang Terdaftar di Bursa Efek Indonesia (BEI) Periode 2013-2016. Journal of Management, 4(4).

Astika, I.B.P. 2017. Harga Referensi dan Return Expectation dalam Employee Stock of Option Plan. Jurnal Keuangan dan Perbankan, 14(1).

Barberis, N., Mukherjee, A., \& Wang, B. 2016. Prospect Theory and Stock Returns: An Empirical Test. The Review of Financial Studies, 29(11), 3068-3107.

Fadlillah Muhammad. 2006. Analisis Tingkat Pengembalian Awal Saham-Saham IPO pada Pasar Modal Syariah (Studi Empiris pada Jakarta Islamic Index di Bursa Efek
Jakarta). Tesis. Jakarta: Universitas Islam Negeri Syarif Hidayatullah.

Handayani, R. \& Zulyanti, N.R. 2018. Pengaruh Earning per Share (EPS), Debt to Equity Ratio (DER), dan Return on Assets (ROA) Terhadap Return Saham pada Perusahaan Manufaktur yang Terdaftar di BEI. Jurnal Manajemen, 3(1), 615-620.

Kanter, A. B., \& Siagian, J. 2018. Effects of Financial Performance towards Investment Return. Fundamental Management Journal, 2(2), 17-26.

Martono, N. 2010. Metode Penelitian Kuantitatif: Analisis Isi dan Analisis Data Sekunder (sampel halaman gratis). Raja Grafindo Persada.

Prasetia Yusi. 2018. Studi Analisis Laporan Keuangan dan Return Saham pada Perusahaan di Jakarta Islamic Indonesia dalam Berinvestasi. Muslim Heritage, 3(1), 61-86.

Rahma, A.A., Elfiswandi, E., \& Putri, I.P. 2017. Analisis Perbandingan Return Saham dan Volume Perdagangan Saham Sebelum dan Sesudah Right Issue. Majalah Ilmiah UPI YPTK, 24(1).

Suharli, M. 2006. Studi Empiris terhadap Dua Faktor yang Memengaruhi Return Saham pada Industri Food \& Beverages di Bursa Efek Jakarta. Jurnal Akuntansi dan Keuangan, 7(2), 99-116.

Ulupui, I.G. 2007. Analisis Pengaruh Rasio Likuiditas, Leverage, Aktivitas, dan Profitabilitas Terhadap Return Saham (Studi Pada Perusahaan Makanan dan Minuman dengan Kategori Industri Barang Konsumsi di BEJ). Jurnal Ilmiah Akuntansi dan Bisnis. www.idx.co.id

https://investasi.kontan.co.id/news/tumbuh-paling-tinggi-prospek-saham-sektor-pertambangan-makin-terbatas. 